\title{
Scientific Development of Socio-Ethical Construction of Ecological Marketing
}

\section{Ulyana A. Pozdnyakova}

Ph.D. in Economics, Volgograd State Technical University, wua@list.ru

Yulia I. Dubova

Ph.D. in Economics, Volgograd State Technical University, dubovaui@mail.ru

Igor I. Nadtochiy

Doctor of Science in Philosophy, G.F. Morozov Voronezh State Forest Engineering University, inad@yandex.ru

Olga V. Klimovets

Doctor of Science in Economics, Academy for Marketing and Socio-Informational Technologies, new_economics@mail.ru

\author{
Aleksey F. Rogachev \\ Volgograd State Agricultural University, rafr@mail.ru \\ Vyacheslav V. Golikov
}

Ph.D. in Economics, Volgograd State Agricultural University, Volgograd, Russia

Doi:10.5901/mjss.2015.v6n5s1p278

\section{Abstract}

At present, modern society pays more and more attention to the health. This is due to wide expansion of informational propaganda as to aggravating state of natural environment, messages from mass-media, and advertising of ecologicallyoriented manufacturers. This informational propaganda forms ecological literacy of consumers and the understanding that environment is aggressive and unsafe, thus motivating them to prefer products which are favorable for health. The purpose of this scientific article is substantiating new approaches to promotion of goods and services, which will allow cultivating ecological literacy of consumers as a basis for formation of consumer preferences and tastes. This purpose is reached by means of considering economic content of ecological marketing as a modern marketing construction, transformed by means of subjects of entrepreneurship and managers of regulatory authorities into a tool for development of consumer market under the influence of aggravation of the state of environment, which will be a practical vector for sustainable development of the regions of Russia in a rapidly globalizing world.

Keywords: ecological marketing, ecological products, ecological management of enterprise.

\section{Introduction}

According to various researches, the Russians prefer safe food, which is of top-quality and conforms to the local climate, to similar foreign products. This fact is a "marketing signal" for more active implementation and development of ecological innovations, which in close perspective should be realized by Russian enterprises and public authorities.

Modern society strives for purchasing and consuming products with better quality and for improving and preserving their living environment. This need is unique, so the way for satisfying it should be unique as well. In order for business to be successful, it has to understand the needs of consumers and satisfy them, which is a classical definition of marketing, which should be a basis for further work. After considering certain existing notions of "marketing" of Russian and foreign authors, it became clear that almost all definitions were formulated by the authors which used the manufacturers' priorities as a foundation and didn't take the consumers' interests into account. The very sense of definitions contradicts the fundamental law of preservation of Life development, formulated in the scientific works of V.I. Vernadskiy, P.G. 
Kuznetsov, O.L. Kuznetsov, and B.E. Bolshakov. According to this law, Human, in terms of technical innovations, has the power over the nature and is a powerful geological force himself - but, trying to reach his goals, Human is dependent on Nature. Violation of this postulate and lack of methods and means for coordination of managerial decisions and programs with the law of Life preservation is the main reason for the global systemic crisis in relations between society and nature.

From the position of the viewed problematics, the article should correct the classical definition of marketing: marketing (narrowly) is implementation of business processes for satisfying consumer's needs by manufacturer. In other words, marketing (broadly) is a strategy of manufacturers when effective satisfying consumer's needs and solving problems of modern society lead to success of enterprises.

\section{Research Methods}

Ecological audit (expertise, controlling), ecological marking, ecological advertising, and other ecologically-oriented innovations are inseparable components of strategies for development of many foreign enterprises, which is caused by a range of existing tendencies.

Firstly, in modern economy, natural resources are spent irrationally and volumes of waste increase due to growth of consumption and production. Thus, for example, "...average citizen of any country of the Organization for Economic Cooperation and Development produces $560 \mathrm{~kg}$ of municipal refuse per annum; all 27 countries (except for 3 countries) which provide their data produced more refuse per capita in 2000 than in 1995. In 2002, average Norwegian produced $354 \mathrm{~kg}$ of refuse, which is by $7 \%$ more than in the previous year". Meanwhile, "...Americans are global leaders for refuse, producing $51 \%$ more municipal refuse per capita than any other average citizen of other country of the Organization for Economic Cooperation and Development".

Secondly, the system of global economy features the active reduction of energy resources due to growth of urbanization of population; the areas of agricultural lands of high quality decrease due to the use of intensive type of husbandry. Thus, "studies show that the layer of sea weeds reduces annually by $0.01-0.02 \%$, tropical forests - by $0.8 \%$, sea-fish take $-1.5 \%$, territory of water ecosystems - by $2.4 \%$, and mangrove forests disappear very quickly - by $2.5 \%$ annually."

Thirdly, in order for manufactured product to be competitive and to have access to global markets, it has to be certified against the requirements by a "third" party. Implementation of principles of ecological certification is one of the main market tools which significantly increases the level of competitiveness of enterprise's production. Thus, for example, "In New Zealand, the catching of the New Zealand straptail (direct rival for the Russian catching of Pollock) is fully MSCcertified, and annual fish constitutes 100-200 thousand tons. The result of ecological certification became the increase of competitiveness of production in the markets of Europe, the USA, Asia, and, consequently, its price growth by $30 \%$ (around USD 70 million of additional profit annually)".

Fourthly, at present, modern society pays more attention to health and life quality due to increased anthropogenous influence which aggravates the ecological situation, including the situation with provision of food and water. "The proof of global degradation of environment is Live Planet Index (LPI): with the help of this indicator, introduced by the World Wildlife Fund, the health of forest, sea, freshwater, and other natural ecosystems is measured. This index showed 35\% aggravation of ecological well-being of the planet, beginning from 1970".

Fifthly, the industry of production of genetically modified products expands, thus threatening the health of the population. GMPs are a dangerous threat which hinders a normal development of ecologically rational agricultural practice that provides the safety of products. New scientific data appears which confirms the facts of negative influence of GMP on principal animals, for which all processes in the body go faster than for human. In the USA, where GMP are widely used, the level of food allergies in recent years grew by 6-10 times.

Another factor for formation of ecologically-oriented strategies is wide-scale expansion of informational propaganda on worsening state of ecological situation; this propaganda, coming from mass-media, is dangerous and unsafe.

The above mentioned tendencies stimulate the consumers to prefer the products of high quality, and enterprises and representatives of science - to develop new methods of production and promotion of products, cultivating ecological culture of manufacturers as means for managing the demand for production of ecologically-oriented enterprises, and ecological culture of manufacturers - as a means for solving the emerging problems in modern society. However, the aspects of production or promotion of ecological products are not developed in theoretical or practical plane. Up to present, only the necessity for ecological responsibility of enterprises before society was realized, and the formalized directions and forms of its realization were absent. The authors of Russia and CIS countries didn't write enough works for study of the market of ecological products and didn't determine the tools for managing this market. At that, other countries fully studied these issues, which influenced the perspectives of the development of the market of ecological products 
abroad.

In our opinion, the very concept of ecological marketing is a tool which allows managing the preferences of modern consumers and being more competitive, on the one hand. On the other hand, it allows being a tool aimed at satisfying the population's needs for ecologically clean products, providing ecological security, acquiring new niches in the global market of ecological products, reaching well-balanced combination of interests of the state and business in the sphere of rational natural resource use and cultivating ecological culture of consumers [Volosatova, 2014]. One way or another, concept of ecological marketing allows reaching sustainable development of the territory in the long-term.

Fig. 1 shows a chain of measures which create a system of a market of ecological products and formation of ecologically-oriented conscience of society, which shows that development of instrumentarium of ecological marketing and its staged implementation at enterprises may lead to development of the market of ecologically clean products through emergence of various initiative ecological activities and satisfying consumer's demand. Development of the market of ecological products will allow solving ecological problems, increasing enterprises' profits, increasing material well-being of society, and will bring to life the realized necessity for development of new programs of production certification [Harkova, 2014].

Solving the above mentioned tasks in the systems of ecological management of enterprises will certainly facilitate the realization of the principles of concept of sustainable development and formation of the notion of ecological production, i.e., wide initiative ecological activity of enterprise, often viewed as modern production, which may be realized together with main products and services. At that, the enterprise makes an independent decision as to manufacture of the product and spending resources and costs for that. Imitation of manufacture or manufacture of low-quality production can bring temporary limited profits, but are useless in whole and often a negative factor in the market in the long-term, limiting demand and offer. Development of the system of ecological management of enterprise facilitates emergence and formation of notions which are important for the whole consumer society and market subjects: emergence of new means and methods of marketing - ecologically-oriented, formation of ecological production, satisfaction of modern consumer demand on products, development of the market of ecological goods and services, formation of programs for certification of ecological products, preservation of quality of environment, purchase of ecological products, and formation of ecologically-oriented conscience of the society.

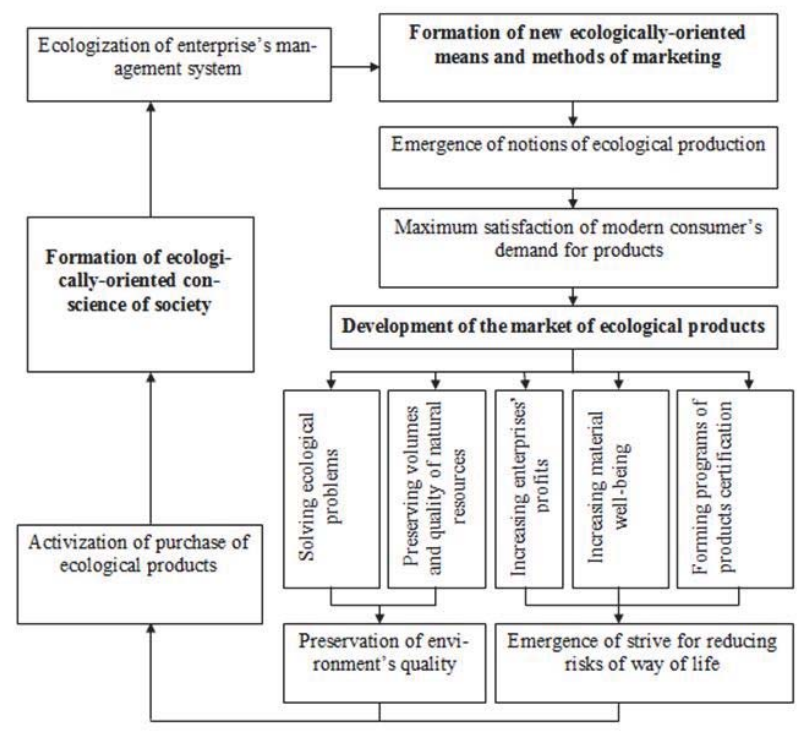

Figure 1. System of goals and tasks, aimed at the development of the market of ecological products

\section{Analysis Results}

Prevention and reduction of influence of entrepreneurial society through manufacture of mass consumption production on 
the environment and creation of the system of ecological management and regulation facilitate the effective formation of demand and offer in the market and emergence of additional market possibilities, related to additional economic benefit (Fig. 2).

If marketing is the process that unites development and realization of processes of economic activities of organization, pricing, and promotion to the market and sale of products, ecological marketing is not just a new conceptual approach but a tool for developing and using methods and means for survival. Ecological marketing offers possibilities not only for new implementation of the process of strategic development but forms directions and methods for solving many issues, directly related to emergence of ecological risk [Dahlstrom, 2010].

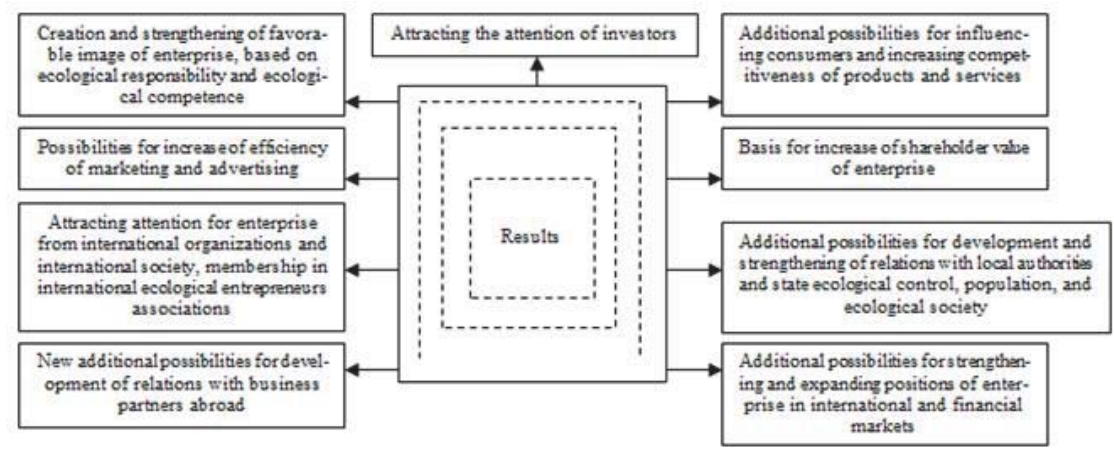

Figure 2. Positive results of ecological marketing

Thus, ecological marketing is a conception of marketing which allows planning the manufacture of ecologically clean products and providing optimal balance between social and economic indicators during the whole life cycle of production, which is a landmark of successful elimination of influence of natural risks and possible anthropogenic influence.

The main principles of ecological marketing include the foundation on ecological motivation, timely problems solving, responsibility for ecological consequences, emerging as a result of making managerial decisions of any level, and priority for solving ecological problems.

Main tasks of ecological marketing include setting ecologically safe productive processes, providing ecological compliance of all productions of a company, achieving optimal ecological-economic balance (maximal result with minimal damage), prevention of negative anthropogenous influence on the nature in the process of production, consumption, or utilization of issued products; turning ecological limitations into new possibilities for the growth of productive activities, renewing production according to social responsibility before consumers and creating the "green" image in the eyes of society, and stimulation of nature protection initiatives which reduce the expenses or facilitate growth of income.

\section{Acknowledgments}

This research was made with financial support from the Russian Humanitarian Science Foundation. Project No. 15-2201011 "Theoretical and methodological foundations for marketing provision of innovational development of intellectual resources of the Republic of Belarus and the Russian Federation under the conditions of economic integration (by the example of universities of business type)".

\section{References}

Dahlstrom, Robert, 2010. Green Marketing Management. Cengage Learning, pp: 360.

Grant, John, 2007. The Green Marketing Manifesto. Wiley, pp: 320.

Harkova, N.N., U.A. Volosatova, M.V. Rossinskaya and A.S. Sidorenko, 2014. Peculiarities of Environmental Certification on the Russian Market // World Applied Sciences Journal. Vol. 30. No. 3. pp. 381-383.

Volosatova, W.A., P.V. Shvagerus, E.G. Popkova and I.M. Budanov, 2014. Conceptual Approach to Ecological Information Marketing System Formation at the Russian Market // World Applied Sciences Journal. Vol. 30. No. 8. pp. 1020-1023. 